\title{
The small-scale squid hand-jig fishery off the northwestern Iberian Peninsula: application of a model based on a short survey of fishery statistics
}

\author{
Fernando Simón, Francisco Rocha *, Angel Guerra \\ Instituto de Investigaciones Marinas (CSIC), Eduardo Cabello 6, 36208 Vigo, Spain
}

Accepted 14 July 1995

\begin{abstract}
A small-scale squid hand-jig fishery targeting the squids Loligo vulgaris and Loligo forbesi exists in the northwestern Iberian Peninsula. Its importance is evaluated using a model based on a short survey of fishery statistics. A total of 46 ports in Galicia operate this fishery. These ports were classified into three categories, according to characteristics relevant to the length of season in the fishery. Aguiño, Cedeira and Mugardos were selected as "model ports" for each of the three categories. The catch per unit effort and total catch were estimated for each of these model ports. Total catch for each port was estimated taking into account the catch obtained in each model port multiplied by a suitable correction factor based on the number of boats in each port. The ports of each of the three categories were considered separately. Thus we can obtain the total catch of the 46 Galician ports where this fishing activity takes place. It was calculated that the small-scale hand-jig fishery unloaded $282 \mathrm{t}$ of squid in Galicia in 1992. The accuracy of the model based on a short survey of fishery statistics was tested by comparing estimates of catches with real squid landing data recorded in Aguiño in 1992. It was observed that the difference between the estimates (15.5 and $14.6 \mathrm{t}$, respectively) was $5.8 \%$. Information on the characteristics of this fishery, seasonality, type and the number of fishing boats is included in this paper, which represents the first step towards assessing the magnitude of the squid resource in the hand-jig Galician fishery.
\end{abstract}

Keywords: Cephalopods; Loligo; Fisheries management; Small-scale fishery; Galicia (NW Spain)

\section{Introduction}

The loliginid squid fishery in Spain is centred on two species: Loligo vulgaris Lamarck, 1797 and Loligo forbesi Steenstrup, 1856. Most catches are of L. vulgaris, which is the

* Corresponding author. Tel: 34 (86) 231930; fax: 34 (86) 292762. 
most common species in the Atlantic and the only one present in the Mediterranean in appreciable quantities. L. forbesi is caught along the Atlantic coast. It is impossible to determine the amount of $L$. forbesi and $L$. vulgaris since both species are included in the official fishing statistics as L. vulgaris (Guerra and Pérez-Gándaras, 1983; Guerra et al., 1994). In the northwestern Iberian Peninsula (Galicia), both these squid species are caught as a by-catch in the multispecies trawler fishery and by direct small-scale hand-jig fishing (Guerra et al., 1994).

The hand-jig fishery has remained largely unknown, being considered of little importance in contrast to the trawler fishery, from which annual catches have increased to approximately 400 t. A preliminary study (Guerra et al., 1994) showed that the hand-jig fishery was subject to variable exploitation. Catches are not recorded in the official landings statistics, and there are no data on production or exploitation rates. Juvenile, maturing and adult individuals of both species are caught in this fishery. It is estimated that the monthly catch during the 5 months of most intense fishing activity could be of the order of 70-90 t: a figure which would double the total annual catch in Galicia (Guerra et al., 1994).

The particular characteristics of the hand-jig fishery, (i.e., seasonality, variability, dispersion, unsuitability or non-existence of data on catches and effort (Guerra et al., 1994)), make management based on application of models currently in use for multispecies fisheries impossible (Pierce and Guerra, 1994). Gómez-Muñoz (1990) has, nevertheless, developed a simple model for multispecies small-scale fisheries. This model was successfully applied to several fisheries in Mexico with a wide range of fishing methods and similar characteristics to the Galician hand-jig squid fishery. This model involves carrying out a survey among fishermen. The results are then used to estimate the total catch and catch per unit effort (CPUE) during the fishery period. The small-scale hand-jig fishery in Galicia differs from that considered in the study by Gómez-Muñoz (1990) in that it is more specific and uses only one fishing method. This paper describes catch levels and fishery performance from the small-scale hand-jig fishery in Galicia for the first time, based on a simple survey of fishermen carried out from April to November 1993 to estimate the catch levels for 1992.

\section{Methods}

From data on ports in Galicia, obtained during a monthly squid sampling programme between January 1991 and December 1992, five representative fishing sites of Galicia were. selected. The ports of Cedeira, Finisterre, Mugardos, Bueu and Aguiño (Fig. 1) were visited monthly, between April and October 1993. The squid fishermen were interviewed personally on site. The surveys provided general information on squid fishing, that is, area, fishing season, catches, number of boats in each port, number of trips per month, catch per trip, etc., besides some other necessary data to apply to the chosen model (Gómez-Muñoz, 1990). Twenty-four fishermen were interviewed from the selected ports, which represented about $4.5 \%$ of all fishermen. Inquiries to each fisherman were carried out as many times as was necessary to obtain all the information required.

Between October and November 1993, other 41 small-scale squid fishing sites in Galicia were also visited. In order to classify these fishing sites, the general characteristics of the fishery, number of fishermen and number of boats used in each site were recorded. 


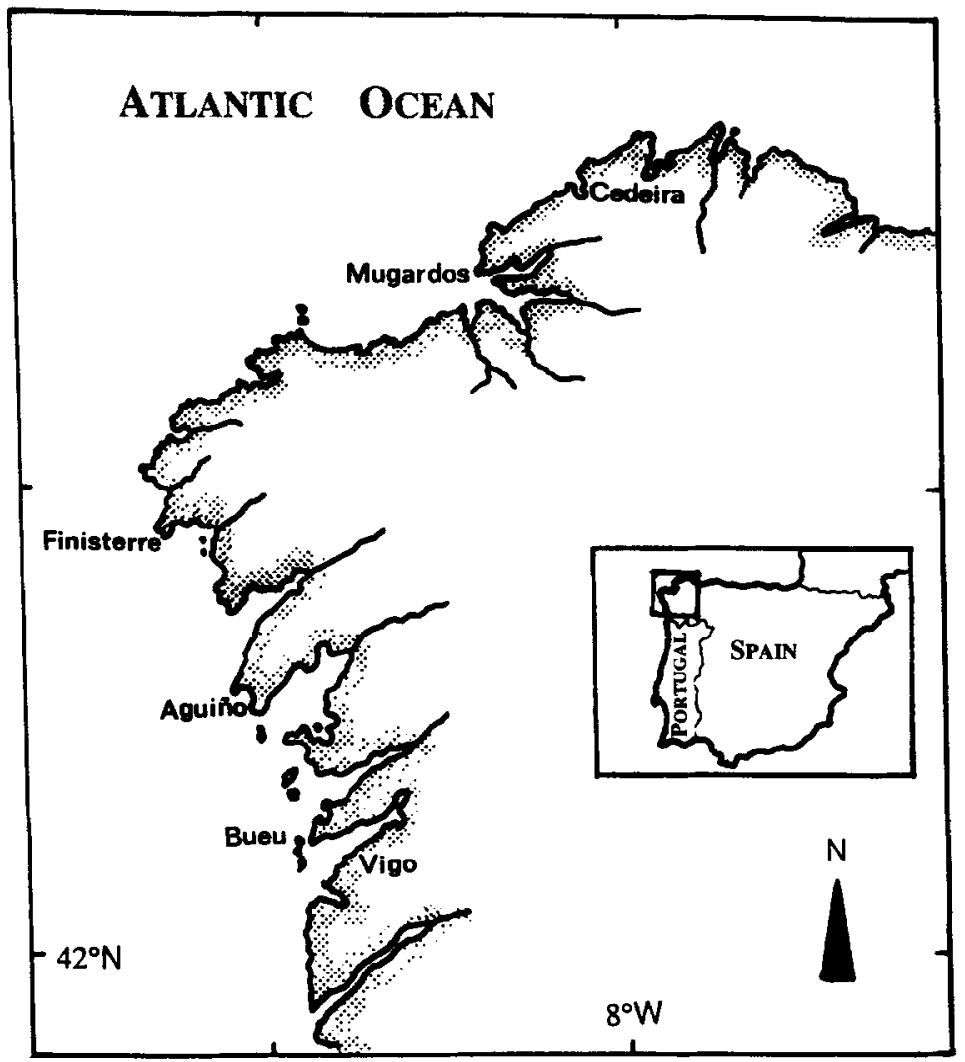

Fig. I. Study area (Galicia, northwest Spain), showing the main ports where the study on the small-scale handjig fishery was made.

Also, in Aguiño, data on the squid landings per boat and per day in 1992 were obtained from the daily sales registers at the port exchange. Aguiño is the only site in Galicia where this is possible. CPUE was estimated monthly from the total weight in kilograms of squid caught per month $\left(C A_{m}\right)$, the average number of trips per boat per month $\left(T_{m}\right)$, and the average number of boats per month present throughout the fishing season $\left(B_{y}\right)$, according to the following equation:

$$
\mathrm{CPUE}=\frac{C A_{m}}{T_{m} * \mathrm{~B}_{y}}
$$

Only in the case of Aguiño is it possible to validate model estimates against empirical data for catch and CPUE. Therefore, the raw data of CPUE and the total catches in $\Lambda$ guiño for 1992 were compared with estimates which generated the model for this port, making it possible to determine the margin of error between the model estimate and the real data.

The use of the model by Gómez-Muñoz (1990) to calculate the total catch of squid by the small-scale hand-jig fishery in Galicia involved the following steps: 
(A) Obtaining TE, an auxiliary variable ( $Z$ in Gómez-Muñoz, 1990) which, proportionally, corresponds to the elapsed time between the month when maximum catch occurs and the end of the fishing season, calculated using the equation:

$$
T E=\frac{I\left(S+L-M_{\max }-1\right)}{M_{\max }-S}
$$

where $S$ represents the month when the fishing season commences (e.g., January is 1 ), $L$ is the length of the fishing season in months, $M_{\max }$ is the month when maximum catch occurs, and lastly, $I$ is an estimate of the relative rate of decrease in catch (slow decrease, $I=1$; intermediary decrease, $I=2$; rapid decrease $I=3$ ). In this case, it was observed that squid catches experienced a rapid decrease, with a maximum of catches moving to the right, that is, towards the end of the fishing period. Therefore, the maximum catch occurs in the beginning of the fishing season.

(B) Calculation of $f_{(x)}$ using the equation:

$$
f_{(x)}=\mathrm{e}^{-x^{2} / 2}
$$

where $f_{(x)}$ represents the bell-shaped function relating CPUE per trip and time in months.

(C) In the case of a given value of time $t$ within the fishing season, the corresponding value of $x$ to evaluate $f_{(x)}$, in month $t$, is obtained from:

$$
x=\frac{I(t-S-L+1)+T E(t-S)}{L-1}
$$

These values are included in the interval $(-I, T E)$. This expression is valid only when the maximum catch occurs at the beginning of the fishing season (Gómez-Muñoz, 1990), which is the case for this squid hand-jig fishery.

(D) Obtaining the monthly CPUE $\left(C_{t}\right)$ according to the expression:

$$
C_{l}=\frac{C_{\max }\left(f_{(x)}-f_{(I)}\right)+C_{\min }\left(1-f_{(x)}\right)}{1-f_{(I)}}
$$

where $f_{(l)}$ corresponds to the value of the function estimated in Eq. (3), substituting $x$ for $I, C_{\max }$ and $C_{\min }$ being the maximum and minimum catches, respectively, recorded in the survey.

The most immediate application of this model is in calculating the total catch for each port. Given the characteristics of the fishery studied, the method applied was as follows.

Since the real number of fishing trips made by the whole fleet was unknown, the total catch $(T C)$ was estimated using the equation:

$$
T C=v_{*} B * L_{*} C m
$$

where $v$ is the average number of trips per month per boat from interviews, $B$ is the average number of boats per month in a port and $L$ is the length of the fishing season for each port in months, which is constant among ports in the same categories described below. The average CPUE $(\mathrm{Cm})$ for the entire season was calculated using the expression: 


$$
C m=\frac{\sum C_{t}}{L}
$$

The total catches by the small-scale hand-jig fishery for the whole of Galicia were calculated in the following manner:

(A) Three categories of fishing ports were defined, each with a "model port" which was selected from among the five representative fishing sites where surveys were performed: category A (with Aguiño as "model port"), comprising ports where the geographical and meteorological conditions make squid fishing possible throughout the year; category $B$ (model port Cedeira), constituted by ports where the geographical and meteorological conditions make squid fishing possible only during the summer and autumn months; and category $\mathrm{C}$ (model port Mugardos), formed by ports where sports fishing is practised during the summer months.

(B) To each "model port" an arbitrary fishing power equivalent to the unit was assigned.

(C) The other fishing ports in Galicia were classified into each of the three categories defined.

(D) According to the number of boats in each port, in comparison with those at the model port, the relative fishing power for each fishing site was estimated.

(E) The total annual catch for each of the other ports $\left(T C_{(p)}\right)$ was calculated based on the total catch for each model port $\left(T C_{(t)}\right)$, according to the expression:

$$
T C_{(p)}=\left(\frac{V_{p}}{V_{1}}\right) * T C_{(1)}
$$

where $V_{t}$ and $V_{p}$, respectively, are the total number of estimated fishing trips per fishing season for the model port and the fishing site, calculated according to:

$$
V_{(i)}=U_{*} B * L
$$

Finally, the total squid catch in the small-scale hand-jig fishery for 1992 was estimated by summing up the catches calculated for each fishing site on the Galician coast for that year.

\section{Results}

\section{3.l. Description of the fishery}

This hand-jig fishery which specifically targets squid, L. vulgaris and L. forbesi, is exploited by three types of fishermen: retired, professionals and sports fishers. The retired fishermen are the majority, whereas the professionals are active only when the yield is high. The sports fishermen fish squid only as a hobby during the summer holidays and at weekends.

The fishing fleet comprised an average of 555 boats during 1992 in Galicia. These are wooden craft from 2 to $4 \mathrm{~m}$ long, which are rowed or are equipped with small 4-5 h.p. outboard motors. There are larger boats, from 5 to $12 \mathrm{~m}$ in length with more powerful 


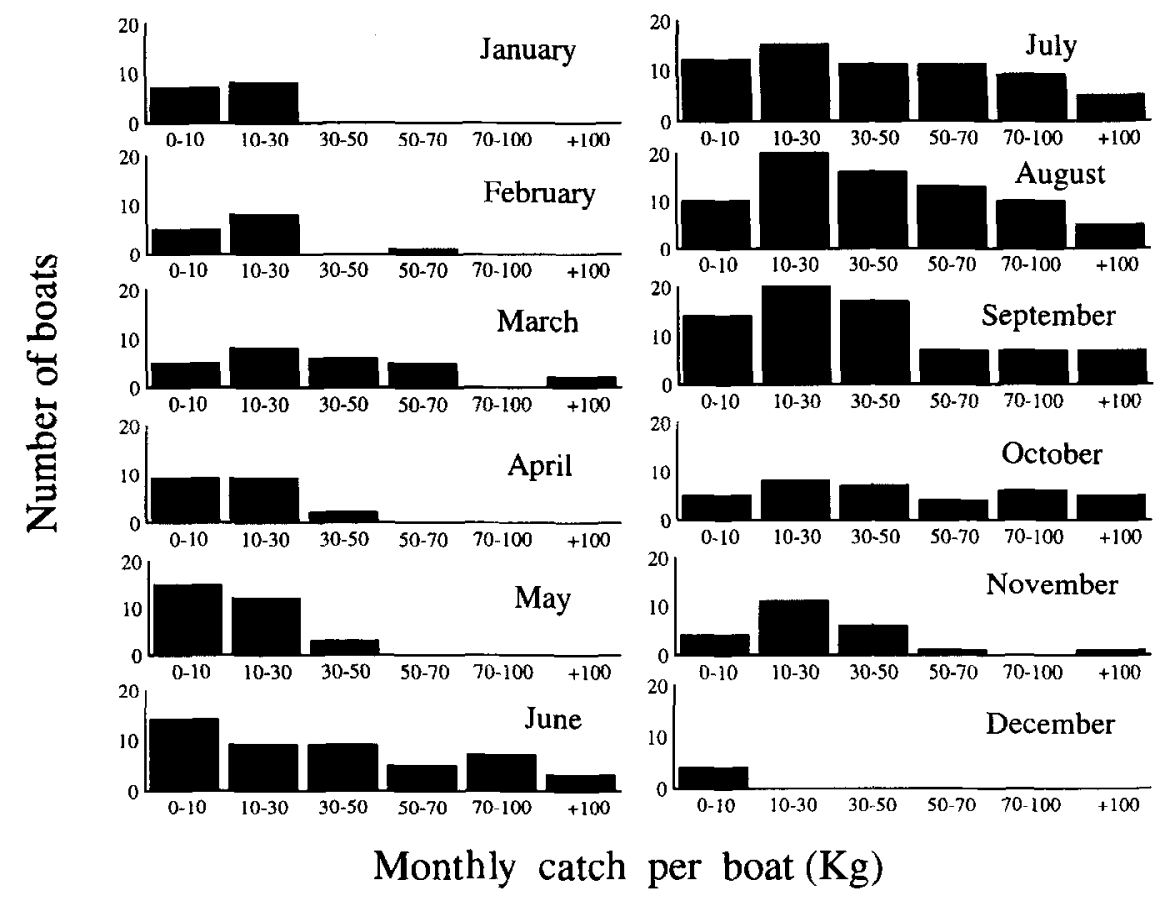

Fig. 2. Number of boats and monthly catches per boat of Loligo spp., in the port of Aguiño, for 1992.

engines ranging from 12 to 60 h.p. In the northern zone of Galicia where small vessels fish further out at sea than in the south, 30-32 h.p. engines are the most commonly used.

Squid jigging is mostly carried out by single boats manned by one fisherman. Lights are not used to attract squid. Squid are fished in shallow waters: from the pier or small fishing boats. Inside the rias (drowned tectonic valleys), squid are mainly caught at depths of between 4 and $22 \mathrm{~m}$. In less sheltered areas or outside the rias, the most common depth is $40 \mathrm{~m}$. Catches are generally made in the early hours of the morning, although fishing also takes place before nightfall. On the northern side of Galicia, L. vulgaris and L. forbesi are caught approximately equally, whereas on the southwestern side L. vulgaris is the more frequent catch.

The length of the fishing season varies, according to the geographic location of the port and the meteorological conditions. In the case of sheltered sites, the fishery may last the whole year. At other more exposed sites, the fishing season may be during only the summer and autumn months. In all these cases, fishing days are restricted to when the sea is calm. All squid caught in this fishery are consumed locally and fresh.

\subsection{Catches in Aguiño for 1992}

Fig. 2 shows the monthly variation in the number of fishing boats and the monthly catch per boat in the port of Aguiño for 1992. At this port there were catches throughout the year, the summer and early autumn being the periods of highest fishing activity. 
Table I

Statistics for fishing Loligo spp. and catch per unit effort per month in the sinall-scale hand-jig fishery of Aguiño for 1992

\begin{tabular}{lcccccc}
\hline Month & $B_{y}$ & $v$ & $T_{m}$ & $C A_{m}$ & $C b_{m}$ & CPUE \\
\hline January & 15 & 33 & 2.2 & 158.0 & 10.5 & 2.05 \\
February & 14 & 29 & 2.1 & 216.5 & 15.5 & 2.99 \\
March & 26 & 171 & 6.6 & 929.0 & 35.7 & 4.04 \\
April & 20 & 102 & 5.1 & 277.8 & 13.9 & 1.56 \\
May & 30 & 127 & 4.2 & 429.5 & 14.3 & 2.90 \\
June & 47 & 436 & 9.3 & 1894.5 & 40.3 & 5.83 \\
July & 62 & 513 & 8.3 & 2843.0 & 45.9 & 9.82 \\
August & 73 & 574 & 7.9 & 3249.0 & 44.5 & 11.81 \\
September & 71 & 494 & 7.0 & 3030.0 & 42.7 & 12.44 \\
October & 35 & 231 & 6.6 & 1829.5 & 52.3 & 7.92 \\
November & 2.3 & 87 & 3.8 & 656.5 & 28.5 & 4.96 \\
December & 4 & 5 & 1.3 & 10.5 & 2.6 & 0.24 \\
Annual total & 420 & 2802 & 64 & 15524 & 347 & 67 \\
Annual average & 35 & 233.5 & 5.3 & 1293.7 & 28.9 & 5.5 \\
\hline
\end{tabular}

$B_{1}$., number of boats per month; $v$, average number of trips per month; $T_{m}$, average number of trips per boat per month: $C A_{m}$, total in kilograms of squid fished per month; $C b_{m}$, average number of kilograms fished per month per boat; CPUE, kilograms per boat and trip.

The CPUE in the small-scale hand-jig fishery of Aguiño during 1992 (Table 1) increased from January to March, decreased in April and then increased from May to September, when the maximum CPUE of $12.44 \mathrm{~kg}$ per boat per trip occurred. The total squid catch in Aguiño for 1992 was $15.5 \mathrm{t}$.

\subsection{Types of ports}

A total of 46 ports and sites in Galicia operate a small-scale hand-jig fishery, with an average fishing fleet of 555 boats during 1992 in Galicia (Table 2). These ports were classified into the three categories described.

Category A: Model port, Aguiño. Twelve ports are included in this category (Table 2).

Category B: Model port, Cedeira. Twenty-seven ports are included in this category (Table 2).

Category C: Model port, Mugardos. Seven ports are included in this category (Table 2).

\subsection{Estimates based on the model}

Twenty-four fishermen were interviewed from the ports of Aguiño, Cedeira, Mugardos, Finisterre and Bueu. Based on these data, the CPUE for each port was estimated for 1992 (Table 3).

The monthly CPUE calculated from the sales statistics recorded in the port of Aguiño and the estimated CPUE from the model (Fig. 3) showed no significant differences $(r=0.89, " * P>0.001, f d=10)$. The empirical annual catch was similar to the predicted anmual catch ( 15.5 and $14.6 \mathrm{t}$, respectively), with a $5.8 \%$ difference. 
Table 2

Ports in Galicia where there is an small-scale hand-jig fishery of Loligo spp. and the estimated fishing power in 1992. relative to the "model port"

\begin{tabular}{|c|c|c|c|c|}
\hline Site & $T P$ & $B$ & $V_{p}$ & Fishing power \\
\hline Aguiño:" & A & 33 & 2376 & $1.00^{a}$ \\
\hline Aldán & A & 2 & 144 & 0.06 \\
\hline Bueu & A & 30 & 2160 & 0.91 \\
\hline Cabo de Cruz & $\mathrm{A}$ & 40 & 2880 & 1.21 \\
\hline Cee & A & 2 & 144 & 0.06 \\
\hline Corcubión & A & 2 & 144 & 0.06 \\
\hline Finisterre & $\mathrm{A}$ & 30 & 2160 & 0.91 \\
\hline Isla de Arosa & $\mathrm{A}$ & 10 & 720 & 0.30 \\
\hline Lorbe & A & 5 & 360 & 0.15 \\
\hline Miño & $A$ & 5 & 360 & 0.15 \\
\hline Muros & A & 30 & 2160 & 0.91 \\
\hline Sada & $\mathrm{A}$ & 30 & 2160 & 0.91 \\
\hline Cedeira" & B & 25 & 1225 & $1.00^{\mathrm{a}}$ \\
\hline Aguete & B & 20 & 980 & 0.80 \\
\hline Barquero & B & 1 & 49 & 0.04 \\
\hline Baiona & B & 10 & 490 & 0.40 \\
\hline Burela & B & 10 & 490 & 0.40 \\
\hline Camariñas & B & 30 & 1470 & 1.20 \\
\hline Camelle & B & 10 & 490 & 0.40 \\
\hline Cangas & B & 7 & 343 & 0.28 \\
\hline Cariño & B & 35 & 1715 & 1.40 \\
\hline Cayón & B & 10 & 490 & 0.40 \\
\hline Corme & B & 10 & 490 & 0.40 \\
\hline O Grove & B & 5 & 245 & 0.20 \\
\hline Escarabote & B & 4 & 196 & 0.16 \\
\hline Espasante & B & 10 & 490 & 0.40 \\
\hline Esteiro & B & 10 & 490 & 0.40 \\
\hline Ezaro & B & 2 & 98 & 0.08 \\
\hline Foz & B & 15 & 735 & 0.60 \\
\hline Laxe & B & 8 & 392 & 0.32 \\
\hline Lira & $\mathrm{B}$ & 2 & 98 & 0.08 \\
\hline Malpica & B & 15 & 735 & 0.60 \\
\hline Marín & B & 10 & 490 & 0.40 \\
\hline Moaña & B & 2 & 98 & 0.08 \\
\hline Muxía & $\mathbf{B}$ & 4 & 196 & 0.16 \\
\hline Ribadeo & B & 10 & 490 & 0.40 \\
\hline Rinlo & B & 2 & 98 & 0.08 \\
\hline Vicedo & $\mathrm{B}$ & 1 & 49 & $0 . \cap 4$ \\
\hline Vivero & $\mathbf{B}$ & 17 & 833 & 0.68 \\
\hline Mugardos ${ }^{i}$ & $\mathrm{C}$ & 10 & 350 & $1.00^{\circ}$ \\
\hline Ares & $\mathrm{C}$ & 4 & 140 & 0.40 \\
\hline Pindo & $\mathrm{C}$ & 12 & 420 & 1.20 \\
\hline Porto do Son & $\mathrm{C}$ & 8 & 280 & 0.80 \\
\hline Portosin & C & 8 & 280 & 0.80 \\
\hline Rianxo & C & 1 & 35 & 0.10 \\
\hline Vilaxoan & $\mathrm{C}$ & 8 & 280 & 0.80 \\
\hline
\end{tabular}

$T P$, lype of poit ( A, B or C); $B$, average number of boats per month. $V_{p}$, estimated total number of trips per fishing season.

"Model port. 
Table 3

Average catch per unit effort and total catch for the small-scale hand-jig fishery in five ports in Galicia

\begin{tabular}{llrrrr}
\hline Port & $S$ & $L$ & $v$ & $C m$ & $T C$ \\
\hline Aguiño & 1 & 12 & 6 & 6.15 & 14614 \\
Cedeira & 6 & 7 & 7 & 5.78 & 15660 \\
Finisterre & 1 & 12 & 7 & 6.74 & 12128 \\
Mugardos & 5 & 6 & 6 & 2.93 & 1230 \\
Bueu & 1 & 12 & 5.49 & 11860 \\
\hline
\end{tabular}

$S$, month starting the fishing season (e.g. $\mathrm{I}$ is January); $L$, length of the fishing season in months; $v$, average number of trips per month; $C \mathrm{~m}$, average CPUE (kg per trip per month); $T C$, total catch $(\mathrm{kg})$.

From Eqs. (6) and (8) and values of Table 2 and Table 3, the total catch for the 46 Galician ports was estimated. This catch rose to $281.8 \mathrm{t}$ in 1992 . By port type, these catches were distributed as follows: category A: $34.4 \%$; category B: $63.4 \%$; category C: $2.2 \%$.

The price of squid at first sale ranged from $£ 3.90$ to $£ 8.90$ sterling per $\mathrm{kg}$. On the basis of an average value of $£ 6.50$ sterling per $\mathrm{kg}$, this fishery generated approximately $£ 1.8$ million sterling in 1992.

\section{Discussion}

Although the small-scale hand-jig fishery for loliginid squid also exists locally in various areas of the northeastern Atlantic and the Mediterranean (Worms, 1983; Sánchez, 1988; Cunha and Moreno, 1994; Guerra et al., 1994), only in the Azores, where the fishery targets L. forbesi, has it been described in detail (Martins, 1982; Porteiro, 1994). The similar characteristics of these small-scale fisheries, particularly along the coasts of Italy, Portugal and other regions of Spain, make it possible for models, such as the one by Gómez-Muñoz

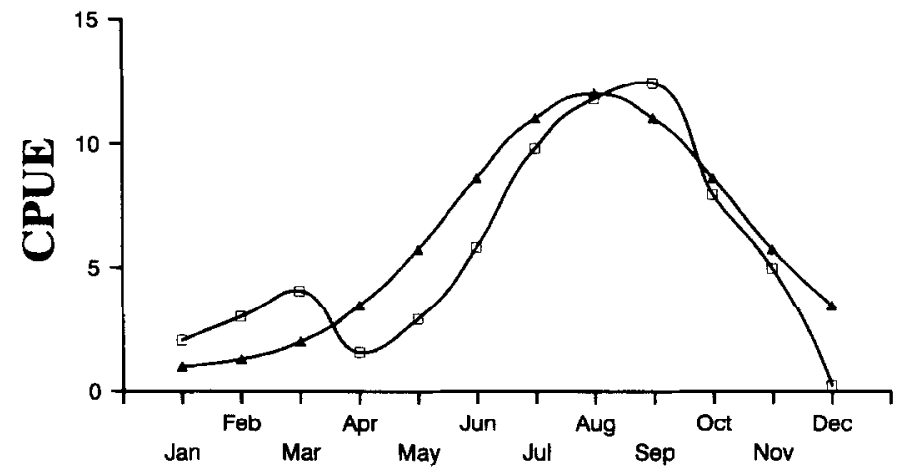

1992

Fig. 3. Monthly variation of the catch per unit effort (CPUE), in kilograms per trip per boat, in the small-scale hand-jig fishery of Loligo spp., in Aguiño, for 1992. Squares, CPUE calculated on squid sales data: triangles, CPUE generated by the Gómez-Muñoz ( 1990) model. 
(1990) based on personal interviews with fishermen, to be useful for evaluating them.

This model requires certain initial information which is easily obtainable. However, since this information is based on the appraisals and memory of the fishermen, it is necessary to interview several at each port to obtain an average value. The greater the number of interviews, the more accurate are estimates of model parameters. It appears that the most reliable are the average values of the $C_{\max }$ and $C_{\min }$, as well as the month when the $C_{\max }$ is most frequently attained (Gómez-Muñoz, 1990). Furthermore, if interviews are carried out on a monthly basis over a suitable period of time or during the season with the highest catch, the model parameters have a greater precision, generating more precise estimates of catches.

The main problem when using this model lies in the estimate of total catch for a given fishing site. The average number of fishing boats and monthly trips for each fishing site are difficult to obtain from the survey, owing to the irregularity of the fishery. This is the information which causes the greatest deviations in the calculation of total catches, and so it is necessary to exercise extreme caution when obtaining it.

The model of Gómez-Muñoz was used to generate catch estimates for the port of Aguiño which are close to the real data obtained at the fish exchange. It must be pointed out, however, that there is a certain percentage of catch which does not appear at the fish exchange. In the case of Aguiño, this percentage is very low, although at other ports in Galicia it may comprise almost the whole catch. It is extremely difficult, therefore, to compare model estimates of catch with that from sales data for this fishery for other ports.

Squid caught in this fishery ( $282 \mathrm{t}$ ) in 1992 was below the $400 \mathrm{t}$ per year figure indicated by Guerra et al. (1994). In Galicia, since the trawler fishery contributes approximately 400 t per year of squid (Guerra et al., 1994), the small-scale hand-jig fishery would comprise $41.3 \%$ of the total catch $(682 \mathrm{t})$. Given the value of hand-jigged squid ( $£ 3.90-£ 8.90$ sterling $/ \mathrm{kg}$ ), catches would generate $\mathfrak{£} 1.8$ million sterling, whereas squid from the trawler fishery, sold at a lower price ( $£ 2.80-£ 4.40$ sterling $/ \mathrm{kg}$ ), would generate $£ 1$ million sterling per year; that is, the hand-jig fishery represents $64 \%$ of the income from squid fishing in Galicia. The income obtained per fisherman in the small-scale fishery, however, is so sporadic that exclusive dedication to this activity is not feasible, as this necessarily requires a change of target species and fishing gear, due to the seasonality of catches.

Since the jig fishery is specific and localized, it may be monitored with precision. This is difficult, however, owing to the characteristics of the fishermen (retired, professionals and sport fishers), and also to the type of legislation in force. Local legislation causes most of the hand-jigged squid to be sold outside the fish exchange and, as a result, this is not officially recorded.

Although the L. vulgaris and $L$. forbesi fisheries in Galicia appear to be stable and not overexploited (Guerra et al., 1994), a more rational, controlled management should be introduced to improve harvesting of these species. The use of models, such as the one by Gómez-Muñoz (1990), marks a first step towards an assessment of this small-scale fishery. Continued study, with monthly sampling of size frequencies and following microcohorts in the population to broaden existing biological information (Guerra and Rocha, 1994), would lead to a greater understanding. This may then make it possible to apply frequently used models in other cephalopod fisheries (Pierce and Guerra, 1994). 


\section{Acknowledgements}

We thank Mr. F. Casas for his invaluable cooperation on the sampling, and Dr. B.G. Castro, the members of the Ecofisiology of Cephalopod Group at the Instituto de Investigaciones Marinas (CSIC), Vigo, and an anonymous referee for assistance and advice. Special acknowledgement and gratitude are due to the fishermen and personnel, particularly in Aguiño, at the ports where information was compiled for this paper. Our thanks also to Mrs. M. de los Angeles Vázquez for information on prices and catches in Baiona and to Ian Emmett for preparation of the English text. This work was financed by two projects under the auspices of the European Union (FAR, MA.1.146 and AIR1-CT92-0573).

\section{References}

Cunha, M.M. and Moreno, A., 1994. Recent trends in the Portuguese squid fishery. Fish. Res., $21: 231-241$.

Gómez-Muñoz, V.M., 1990. A model to estimate catches trom a short tishery statistics survey. Bull. Mar. Sci., $46(3): 719-722$.

Guerra, A. and Pérez-Gándaras, G., 1983. Recursos mundiales de cefalópodos: situación actual y perspectivas. Inf. Tec. linv. Pesy., 102-104: 1-141.

Guerra. A. and Rocha, F., 1994. The life history of Loligo v'ulgaris and Loligo forbesi (Cephalopoda: Loliginidae) in Galician waters (NW Spain). Fish. Res., 21: 43-69.

Guerra, A.. Sánchez, P. and Rocha, F., 1991. The Spanish fishery for Loligo: recent trends. Fish. Res., 21: 217230 .

Martins. H.R.. 1982. Biological studies of the exploited stock of Loligo forbesi (Mollusca: Cephalopoda) in the Azores. J. Mar. Biol. Assoc. UK. 62: 799-808.

Pierce, G.P and Guerra, A., 1994. Stock assessment methods used for cephalopod fisheries. Fish. Res.. 21: 25528.5.

Porteiro. F.M. 1994. The present status of the squid fishery (Loligo forbesi) in the Azores archipelago. Fish. Res., 21: $243-253$

Sánchez., P., 1988. La pêche artisanale aux Céphalopodes. Rapp. Comm. Int. Mer Médit., 31 (2): 253.

Worms, J., 1983. Loligo nulgaris. In: P.R. Boyle (Ed.), Cephalopod Life Cycles, Vol.1. Species Accounts. Academic Press, London, pp. 143-157. 